\title{
An Experimental Trial of a Dog-Training Program in a Juvenile Detention Center
}

\author{
AUTHOR INFORMATION \\ Eric Grommon* \\ Assistant Professor \\ School of Public and Environmental Affairs \\ Indiana University-Purdue University Indianapolis \\ 801 W. Michigan Street \\ Indianapolis, Indiana 46202 \\ 317.278.9481 \\ egrommon@iupui.edu \\ Dena C. Carson \\ Assistant Professor \\ School of Public and Environmental Affairs \\ Indiana University-Purdue University Indianapolis \\ 801 W. Michigan Street \\ Indianapolis, Indiana 46202 \\ 317.274.8707 \\ carsond@iupui.edu \\ Lauren Kenney \\ Prison Division Program Manager \\ Wyoming Department of Corrections \\ 1934 Wyott Drive, Suite 100 \\ Cheyenne, Wyoming 82002 \\ *Corresponding Author
}

This is the authors' manuscript of the article published in final edited form as:

Grommon, E., Carson, D. E., \& Kenney, L. (2018). An experimental trial of a dog-training program in a juvenile detention center. Journal of Experimental Criminology.

https://doi.org/10.1007/s11292-018-9346-2 


\title{
An Experimental Trial of a Canine-Assisted Activity Program in a Juvenile Detention Center
}

\begin{abstract}
Objectives: This research examines the effect of a dog-training program among juveniles ordered to a county juvenile detention facility in a large, Midwestern city.

Methods: A pre-test, post-test experimental design was constructed to examine changes in selfesteem, empathy, optimism, pessimism, compassion, and social competence between juveniles who were randomly assigned to the canine-assisted activity program and to the standard conditions of the detention center without access to the program. Two-way and repeated measures ANOVA models are used to assess the differential effect of the program.
\end{abstract}

Results: The dog-training program evaluated in this study did not differentially benefit nor did it harm participants in relation to juveniles who received the standard operating practices and procedures of the detention center.

Conclusions: Generalized conclusions about the effectiveness of dog-training programs in secure correctional facilities should not be made from this study. Despite the unique program model structure used in this study, the results demonstrate that once selection effects are mitigated through randomization, the mere exposure to a dog-training program does not translate to improved outcomes. The results raise more questions about the influence of selection effects on reported findings and stimulate inquiry on dog-training program models, research designs used to assess program effects, and the importance of intermediate interventions.

\section{KEYWORDS}

Canine-Assisted Activity; Juvenile; Detention; Experimental Design; Program Evaluation 


\section{AUTHOR BIOGRAPHIES}

Eric Grommon is an Associate Professor within the School of Public and Environmental Affairs at Indiana University-Purdue University Indianapolis. His research interests include corrections, prisoner reentry, and the evaluation of criminal justice programs, policies, and operations. His research has been published in Criminology and Public Policy, Evaluation Review, Journal of Experimental Criminology, Journal of Quantitative Criminology, and Justice Quarterly.

Dena C. Carson is an Assistant Professor within the School of Public and Environmental Affairs at Indiana University Purdue University Indianapolis. Her research interests include youth violence, victimization, gangs and delinquent peer groups. Her recent publications have appeared in Criminal Justice Review, Journal of Crime \& Justice, and Justice Quarterly.

Lauren Kenney earned her Master of Science in Criminal Justice and Public Safety from the School of Public and Environmental Affairs at Indiana University-Purdue University Indianapolis. Lauren is currently the Prison Division Training Program Manager for the Wyoming Department of Corrections. Her research interests include justice system administration, homeland security and emergency management, community capacity building, research methods, and evidence-based programming in correctional settings. 


\section{Introduction}

Dog-training programs in secure correctional facilities can improve the well-being of participants and the operations of host facilities (Cooke \& Farrington, 2016; 2014). Scholars have called for the examination of programs across correctional settings and with the use of experimental designs to improve knowledge on program effects (Cooke and Farrington 2016, 2014; Fournier et al. 2007). Not only is the random allocation of participants to programming missing, there also remains fundamental gaps in the research literature concerning the selfselection of participants in to or out of dog-training programs and the construction of appropriate comparison groups.

Much of what is known about dog-training programs originates from prisons (Britton and Button 2008; Cooke and Farrington 2015; Currie 2008; Hill 2018; Hill 2016; Richardson-Taylor and Blanchette 2001; Turner 2007; van Wormer et al. 2014). Participants in these settings are enrolled for a series of months or years and have loosely regulated access to dogs (Britton and Button 2008; Currie 2008; Fournier et al. 2007). The most rigorous evaluations in these settings are quasi-experimental. Propensity matched studies detail reductions in serious and violent infractions (Hill 2018; Hill 2016; van Wormer et al. 2014) and recidivism rates (Hill 2018; 2016). Studies with unmatched groups report improvements in psychosocial functioning and social skills (Fournier et al. 2007). Reductions in loneliness (Richardson-Taylor and Blanchette 2001) and criminal behavior (Fournier et al. 2007) are also observed. Additional unmatched studies find mixed results on psychosocial outcomes of self-esteem, self-control, depression, and self-efficacy (Gilger 2007; Richardson-Taylor and Blanchette 2001).

Programs have also been implemented in facilities with shorter average lengths of stay than prisons, where participants engage in activities for two to ten weeks (Chianese 2009; Seivert 2014) 
and access to dogs is limited (Harbolt and Ward 2001; Seivert 2014). This type of program structure tends to originate from juvenile detention centers. Detention centers may be a suitable setting to test the efficacy of dog-training programs, particularly if the threat of selection bias can be mitigated through the random assignment of participants who choose to participate in this type of activity. Detention negatively affects mental health and physical well-being of juveniles (Holman and Ziedenberg 2006). Youth placed to detention are 10 times more likely to suffer from major psychoses in relation to the general adolescent population (Fazel et al. 2008). Further, the setting offers little capacity to deliver appropriate treatment services, leaving few opportunities to receive any form of programming (Hockenberry et al. 2016). In combination, these factors may further damage adolescent development and leave juveniles at-risk for future justice system contact. Dog-training programs may offset some degree of harm or risk by cultivating humananimal bonds and a sense of purpose or identity (see Cooke and Farrington 2014), but the evidence to support such claims is underdeveloped.

Studies of programs in detention centers or those targeting juveniles suffer from many of the same methodological limitations as those involving adult prison facilities. Programs have been found to develop or enhance self-efficacy and empathy (Cooke and Farrington 2015; 2014; Davis 2007; Harbolt and Wood 2001; Leonardi et al. 2017; Merriam 2007), improve resident-staff relationships (Merriam 2007), and reduce recidivism (Chianese 2009; Merriam 2007) via quasiexperimental or descriptive case study designs. However, Seivert (2014) finds no improvements in empathy or psychosocial development. This research is the only study to make use an experimental design that assigned juvenile detention center participants to deliver obedience training or the responsibility of walking a dog. No randomization to a pure, "normal conditions" control group was used in this study. 
While the results of dog-training programs demonstrate promise, there remains critical and untested questions about the influence of selection bias on reported outcomes. As one or more comparison groups are integrated into evaluation designs, the anticipated benefits of programs become less conclusive and these results may be driven, in part, by pre-existing differences between participants and non-participants. This study heeds the call of scholars and furthers the body of knowledge in three main areas: 1) it uses an experimental design to minimize selection issues; 2) it includes a control group that experienced "normal conditions" of a secure correctional facility and 3) it tests the application of a short-term program model in a juvenile detention center, where the normal conditions of the facility are more uniformly experienced given the lack of available programming opportunities.

\section{Description of the Dog-Training Program}

The program aims to improve youth development by providing participants with an opportunity to deliver obedience training, bond with dogs, and learn tangible skills. In partnership with the county animal shelter, 12 youth are matched to six shelter dogs and six adult program volunteers that supervise and assist with training. Each dog is paired with two participants and one program volunteer across program sessions to maintain continuity. The program is held monthly and consists of five hour long sessions held across one week. The model most closely resembles those studied by Chianese (2009) and Seivert (2014), but deviates from these two models with its short duration.

In the first session, an experienced dog handler presents information on how to approach and interact with dogs. A certified service dog is present to demonstrate program content and facilitate participant interaction. An overview of behavioral conditioning is provided and 
participants are informed of program rules. Remaining sessions are direct training periods. A lead handler instructs two obedience skills each day and demonstrates techniques to teach commands and positive reinforcement schedules. Volunteers model commands and reinforcements for participants. Participants are responsible for replicating training content and are encouraged to care for their dog by using toys, grooming tools, and treats. Commands become increasingly more complex in subsequent training sessions. On the final day of the program, a closing ceremony is held. Participants demonstrate the obedience training they have learned by directing their dog through a set of commands in front of participants and program staff. Each participant is individually congratulated and receives a graduation certificate. In turn, each shelter dog is provided a certificate of obedience training and statement authored by participants detailing how the dog is to be trained. These documents accompany the dogs as they return to the shelter for public adoption at the end of a program session.

\section{Methods}

The detention center sponsoring this study was a county-operated facility located in a large, Midwestern city. The center receives youth under the age of 18 who await adjudication and youth who have been adjudicated and await transfer to a state facility. This includes juveniles arrested on direct file charges. The facility had a rated capacity of 96 residents and contained six living units, four of which were reserved for males and two for females. One additional unit was used for isolation. Across the time of this study, the average daily population of 84 residents had an average length of stay of 21 days.

The average resident was a 16-17 year-old black male. Thirteen percent of the population was female. Eighteen percent of residents were white, $8 \%$ were two or more races, and $3 \%$ were 
Hispanic or Latino. A larger proportion of residents was between the ages of 15 to $16(52 \%)$ and was followed by residents aged 17 to $18(29 \%)$ and 12 to 14 (19\%). Almost half (49\%) of residents were charged with felony offenses, $35 \%$ were ordered to detention for probation violations, and 16\% were charged with misdemeanor offenses. In proportions of descending order, felony offenses consisted of property, persons, weapon, and drug cases. Misdemeanor offenses involved weapons, persons, drug, and property cases.

An intent-to-treat pre-test, post-test experimental design with random assignment of eligible youth to the program participant group and a normal conditions group was employed. Residents opt-in to be considered for participation through their case manager. Residents who opt-in may then become eligible for participation if they had participated required educational classes; earned sufficient daily points in an internal token economy system used to monitor compliance; had not received a misconduct violation; do not have a history of crime against animals; and had their next court date scheduled after the last program session date. Detention center administrators conducted eligibility screens using a standardized protocol. If a resident was found eligible, they were entered into a lottery and randomly assigned to one of the experimental conditions across a two year period. Straight random assignment procedures were used. Program staff and line-level detention center staff were blind to assignment procedures. The final sample consisted of 310 eligible participants.

All eligible participants were subjected to the normal operations of the detention center, which included educational services from licensed educators each weekday throughout the calendar year and access to case managers, medical professionals, licensed psychologists, legal counsel, and voluntary religious programming. All participants were provided at least one hour of physical education each day and are afforded recreational opportunities. All participants were 
provided access to communal area phones to contact parents or guardians and are permitted two visitations per week. All participants could request to opt-in to special programming activities led by volunteers from the community as they become available. All participants were subjected to facility rules and discipline for non-compliance in a modified token economy.

The Treatment Group was exposed to the dog-training program, while the Control Group experienced the standard conditions of the detention center without access to the dog-training program. Per the standard policy and procedure, members of the control group could participate in other volunteer-led activities if they were available or engage in recreational or leisure activities while the dog-training program was in session. Although the various types of volunteer programs and resident attendance in such programs are not systematically recorded, anecdotal accounts indicate that a majority of volunteer-led programs are unstructured and involve religious or secular mentorship functions. Fifty-seven percent of the sample $(N=177)$ were randomly assigned to the Treatment Group and the remainder were assigned to the Control Group $(\mathrm{N}=133)$.

Data were generated from voluntary pre-program, post-program survey collections. While the pre- and post-program surveys contained the exact same survey items, the ordering of post-program survey items were shuffled to minimize participant recall. Pre-program surveys included a set of five demographic questions. These items include subjects' Race/Ethnicity and Age as well as measures of whether subjects have been previously bitten by a dog (Previously Bitten), have previously observed a dog fight (Previously Observed Dog Fight), and currently have at least one dog at home (Currently Possess Dog).

Six dependent variables were collected. Each variable correspond to psychosocial constructs collaboratively specified as outputs or short-term outcomes during logic model 
development with detention center and program stakeholders. Constructs also relate to elements of positive youth development (Steinberg 2009). Self-Esteem is generally defined as one's favorable or unfavorable attitude toward the self (Rosenberg 1965). The measure consists of eight items and ranges in value from zero to three. Empathy relates to an emotional response to or sympathy for another's feelings or experiences (Bryant 1982). Ranging in value from zero to three, the measure contains 17 items. Optimism and Pessimism respectively relate to one's expectations about the future (Ey et al. 2005). Both variables consist of a set of six items that range in value from zero to three. Compassion is defined as one's treatment of themselves and their ability to view one's feelings of suffering with a sense of concern and connection to others

(Raes et al. 2011). The measure involves seven items and ranges in value from one to five. Social Competence broadly relates to one's beliefs about their social attributes (Harter 1985). This measure assesses one's views about their own social competence in relation to their peers. Five items are used and range in value from zero to three. Electronic supplementary material accompanying this short report details the list of items used to create outcome scales.

\section{Results}

Prior to examining outcomes, it is critical to make a determination of fidelity to the random assignment procedure. As expected, bivariate analyses revealed no statistically dependable differences between the two groups on available pre-treatment demographic characteristics (see Table 1).

[INSERT TABLE 1 ABOUT HERE] 
Outcomes Tables 2 and 3 summarize the results of two-way and repeated measures ANOVA models used to examine the differential effect of exposure to the program on psychosocial functioning. At pre-test, both groups are relatively similar to one another on the primary constructs used in this study. One deviation exists; the Control Group was slightly more pessimistic than the Treatment Group $[F(1,280)=4.07, \mathrm{p}<0.05]$.

\section{[INSERT TABLE 2 ABOUT HERE]}

Repeated measures ANOVA models test whether there were unique changes that differentially affected the Treatment Group. Overall, there were no statistically significant differences between experimental conditions on any of the psychosocial constructs. There were a few substantive trends to note. First, compassion increased over time and improved at a rate that was approximately the same for both groups. Second, empathy, optimism, pessimism, and social competence were largely static. Third, although the rate of change is marginal, self-esteem decreased over time for both groups.

\section{[INSERT TABLE 3 ABOUT HERE]}

Sensitivity Analysis Similar to other pre- and post-test designs, the current study experienced challenges in collecting a post-test survey. The routine activities of the juvenile court and detention center contributed to the rate of attrition. Participants were unable to complete a posttest survey because their court date changed, release orders were executed, or new sanctions were imposed. While there were no differences between participants who completed the post-test and those who did not on pre-treatment demographic characteristics nor on the dependent variables, a multivariate analysis of variance (MANOVA) model indicated that participants assigned to the Treatment Group who were unable to complete the post-test had lower pre-test pessimism scores $(\mathrm{M}=1.00 ; \mathrm{SE}=0.07)$ in relation to similarly situated Control Group members 
$(\mathrm{M}=1.35 ; \mathrm{SE}=0.09)$. While this sensitivity test does raise a concern about differential attrition, it is important to interpret this result within its broader context. First, MANOVA pairwise comparisons indicate significant differences between experimental conditions on pre-test pessimism scores, but there were no differences between participants who did and did not compete the post-test by group. This finding is consistent to those reported in Table 3 . Second, the magnitude of attrition bias is not likely to reverse the overall findings for pessimism. Participants assigned to the Treatment Group who completed the post-test had identical pessimism pre-test scores $(\mathrm{M}=1.10 ; \mathrm{SE}=0.08)$ to those assigned to the Control Group who also completed their post-test $(\mathrm{M}=1.10 ; \mathrm{SE}=0.08)$. Attrition appears to have conservatively biased the overall findings (i.e., raising probability of false negative) instead of amplifying potential pseudo-effects (i.e., raising probability of false positive).

\section{Discussion}

Through the use of an experimental design, participants who opted-in to a short-term dog-training program were randomly assigned to be exposed to the program or to experience the normal conditions of a local juvenile detention center. There is no evidence to suggest that the program under study enhanced the psychosocial functioning of participants. Overall, the findings of this study are consistent with a past randomized trial that assigned juvenile detention center participants to two different forms of canine-assisted activities, but contrast with, and call into question, a small body of quasi-experimental empirical literature that report promising psychosocial outcomes.

Despite the randomized design used here, generalizable conclusions about the effectiveness of dog-training programs should not be made from this study due to the uniqueness 
of the current program. The short duration of the program translates to a small or diluted "dose" of intervention. Further, participants were not provided unlimited access to dogs and dogs were not continuously housed on site. The combination of these two program factors, coupled with a narrow interval between pre- and post-test surveys, raises relevant questions about the strength of the program model. To advance best-practice principles, future research must take care to report dog-training program models with sufficient details on curricula, duration, contact hours, setting, eligibility criteria, participant characteristics, and regulations on access to dogs. In turn, this information can be used to inform meta-analyses to determine what type of model works best for which type of setting and participant.

Two additional limitations must be considered when interpreting results. First, compensatory rivalry and treatment diffusion may have contributed to the overall findings. As indicated in the pre-test survey results (see Table 2), knowledge of being provided with or prevented from an opportunity to participate in the program may have contributed to pre-test differences in pessimism. At no point, however, were members of the Control Group provided access to the program or its dogs while the study was active. This limitation is common to evaluations of dog-training programs (Cooke \& Farrington, 2016; Fournier et al., 2007) and cannot be completely ruled out from this study. Future studies will need to use cluster randomization and other innovative research designs to minimize these internal validity threats.

Second, this study focused on a set of internalizing outcomes (Cooke and Farrington 2016), which are difficult to measure and may not sufficiently change within short periods of time. Yet, these same constructs are central to advancing positive and pro-social youth development (Steinberg 2009). Replications of this work should seek to integrate externalizing 
measures (e.g., misconducts, recidivism) and establish partnerships with physical scientists to measure physiological outcomes used in human-animal bonding research (Baun et al. 1984).

The findings of this research offer important insights for policy and research. First, this study demonstrates that the randomized exposure to a short-term dog-training program does not improve psychosocial outcomes. Given the presence of randomization to mitigate selection bias in this study and its absence in other studies, it will be essential to design future controlled trials of more common, longer-term programs housed in adult prisons. To do so will minimize participant selection issues that may be driving the results of available research. Second, the results of this study can advance dialogue on the role of dog-training programs as an intermediate intervention. It is important to acknowledge that the null results reported in this study indicate that the program was no less effective than standard practice. Anecdotal evidence from participants, detention staff, and the juvenile court signal that the program is held in high regard. Delivery of a dog-training program - even with less than optimal results - provides another outlet for detention center residents; one that supplements educational and recreational activities at relatively low cost (Cooke and Farrington 2014). The lack of harmful results coupled with an inexpensive program that provides an opportunity for participants to give back to the community in tangible or intangible ways may be enough evidence for administrators to sponsor animal-assisted activity programs in their facilities. 


\section{REFERENCES}

Baun, M. M., Bergstrom, N., Langston, N. F., \& Thoma, L. (1984). Physiological effects of human/comparison animal bonding. Nursing Research, 33, 126-129.

Britton, D. M. \& Button, A. (2008). Prison pups: Assessing the effects of dog training programs in correctional facilities. Family Social Work, 9, 75-95.

Bryant, B. K. (1982). An index of empathy for children and adolescents. Child Development, 53, 413-425.

Chianese, N. M. (2009). Girls, jails, and puppy dog tails: An evaluation of the New Leash on Life program. Dissertation, California State University.

Cooke, B. J. \& Farrington, D. P. (2016). The effectiveness of dog-training programs in prison: A systematic review and meta-analysis of the literature. Prison Journal, 96, 854-876.

Cooke, B. J. \& Farrington, D. P. (2015). The effects of dog-training programs: Experiences of incarcerated females. Women \& Criminal Justice, 25, 201-214.

Cooke, B. J., \& Farrington, D. P. (2014). Perceived effects of dog-training programmes in correctional settings. Journal of Forensic Practice, 16, 171-183.

Currie, N. S. (2008). A case study of incarcerated males participating in a canine training program. Dissertation, Kansas State University.

Davis, K. (2007). Perspectives of youth in an animal- centered correctional vocational program: A qualitative evaluation of project pooch. Retrieved from http://www.pooch.org/documents/project-pooch-qualitative-eval.pdf

Ey, S., Hadley, W., Nuttbrock Allen, D., Palmer, S., Klosky, J., Deptula, D., Thomas, J. \& Cohen, R. (2005). A new measure of children's optimism and pessimism: The youth life orientation test. Journal of Child Psychology and Psychiatry, 46, 548-558.

Fazel, S., Doll, H., \& Langstrom, N. (2008). Mental disorders among adolescents in juvenile detention and correctional facilities: A systematic review and metaregression analysis of 25 surveys. Journal of the American Academy of Child \& Adolescent Psychiatry, 47, 1010-1019.

Fournier, A. K., Geller, S., \& Fortney, E. E. (2007). Human-animal interaction in a prison setting: Impact on criminal behavior, treatment progress, and social skills. Behavior and Social Issues, 16, 89-105.

Gilger, C. G. (2007). Cell dogs: No effect of dog training programs on prisoners' self-efficacy. Dissertation, Emporia State University.

Harbolt, T. \& Ward, T. H. (2001). Teaming incarcerated youth with shelter dogs for a second chance. Society \& Animals, 9, 177-182. 
Hill, L. (2018). Becoming the person your dog thinks you are: An assessment of Florida prisonbased dog training programs on postrelease recidivism. Corrections: Policy, Practice and Research (in press). DOI: 10.1080/23774657.2018.1433564.

Hill, L. B. (2016). Becoming the person your dog thinks you are: An assessment of Florida prison-based dog training programs on prison misconduct, post-release employment and recidivism. Dissertation, Florida State University.

Holman, B. \& Ziedenberg, J. (2006). The dangers of detention: The impact of incarcerating youth in detention and other secure facilities. Washington, DC: Justice Policy Institute.

Leonardi, R. J., Buchanan-Smith, H. M., McIvor, G., \& Vick, S. (2017). "You think you're helping them, but they're helping you too": Experiences of Scottish male young offender participating in a dog training program. International Journal of Enviornmental Research and Public Health, 14(8), E945.

Mendel, R. A. (2014). Juvenile detention alternatives initiative: Progress report 2014. Baltimore, MD: The Annie E. Casey Foundation.

Merriam, S. (2007). Discovering project pooch: A special program for violent incarcerated male juveniles. Gilbert, AZ: Discover N' Education Research and Consulting.

Raes, F., Pommier, E., Neff, K. D., \& Van Gucht, D. (2011). Construction and factorial validation of a short form of the self-compassion scale. Clinical Psychology and Psychotherapy, $18,250-255$.

Richardson-Taylor, K., \& Blanchette, K. (2001). Results of an evaluation of the pawsitive directions canine program. Ottawa, Ontario, Canada: Correctional Service of Canada, Research Branch.

Rosenberg, M. (1965). Society and adolescent self-image. Princeton, NJ: Princeton University Press.

Seivert, N. P. (2014). Animal-assisted therapy for incarcerated youth: A randomized-controlled trial. Thesis, Wayne State University.

Steinberg, L. (2009). Adolescent development and juvenile justice. Annual Review of Clinical Psychology, 5, 459-485.

Turner, W. (2007). The experiences of offenders in a prison canine program. Federal Probation, $71,38-43$.

van Wormer, J., Kigerl, A., \& Hamilton, Z. (2017). Digging deeper: Exploring the value of prison-based dog handler programs. The Prison Journal, 97, 520-538. 
Table 1. Demographic Characteristics

\begin{tabular}{llll}
\hline & $\begin{array}{l}\text { Treatment Group } \\
(\mathrm{n}=177)\end{array}$ & $\begin{array}{l}\text { Control Group } \\
(\mathrm{n}=133)\end{array}$ & $\begin{array}{l}\text { Total Sample } \\
(\mathrm{n}=310)\end{array}$ \\
\hline Race/Ethnicity & $65 \%$ & $64 \%$ & $65 \%$ \\
Black & $18 \%$ & $13 \%$ & $16 \%$ \\
White & $6 \%$ & $9 \%$ & $7 \%$ \\
Hispanic or Latino & $11 \%$ & $14 \%$ & $12 \%$ \\
Other & $10 \%$ & & $11 \%$ \\
Age & $47 \%$ & $11 \%$ & $50 \%$ \\
12-14 & $42 \%$ & $53 \%$ & $38 \%$ \\
$15-16$ & $1 \%$ & $34 \%$ & $1 \%$ \\
$17-18$ & & $2 \%$ & $55 \%$ \\
19+ & $50 \%$ & & $4 \%$ \\
Previously Bitten & $5 \%$ & $63 \%$ & $16 \%$ \\
Never & $20 \%$ & $3 \%$ & $19 \%$ \\
Before Age 5 & $19 \%$ & $10 \%$ & $6 \%$ \\
Between Ages 6-10 & $6 \%$ & $18 \%$ & $21 \%$ \\
Between Ages 11-15 & $18 \%$ & $6 \%$ & $22 \%$ \\
Between Ages 16-Above & $25 \%$ & $25 \%$ & \\
Previously Observed a Dog Fight & $17 \%$ & \\
Currently Possess Dog & & & \\
\hline
\end{tabular}

$* p<0.05$ 
Table 2. Pre-Test Survey Standardized Means by Group ( $\mathrm{n}=\mathbf{3 1 0}$ )

\begin{tabular}{|c|c|c|}
\hline & $\begin{array}{l}\text { Treatment Group } \\
\mathrm{M}(\mathrm{SD})\end{array}$ & $\begin{array}{l}\text { Control Group } \\
M(\mathrm{SD})\end{array}$ \\
\hline Self-Esteem & $2.27(0.46)$ & $2.17(0.42)$ \\
\hline Empathy & $1.70(0.27)$ & $1.63(0.30)$ \\
\hline Optimism & $2.31(0.57)$ & $2.37(0.46)$ \\
\hline Pessimism & $1.05(0.63)^{*}$ & $1.21(0.67)^{*}$ \\
\hline Compassion & $3.35(0.57)$ & $3.35(0.57)$ \\
\hline Social Competence & $1.99(0.50)$ & $1.97(0.47)$ \\
\hline
\end{tabular}


Table 3. Repeated Measures ANOVA

\begin{tabular}{|c|c|c|c|c|c|}
\hline & \multirow{2}{*}{$\begin{array}{l}\text { Pre-Test } \\
\text { M (SE) }\end{array}$} & \multirow{2}{*}{$\begin{array}{l}\text { Post-Test } \\
\text { M (SE) }\end{array}$} & \multirow[b]{2}{*}{$\mathrm{F}$} & \multirow[b]{2}{*}{$\mathrm{df}$} & \multirow[b]{2}{*}{$\eta_{\mathrm{p}}^{2}$} \\
\hline & & & & & \\
\hline \multicolumn{6}{|l|}{ Self-Esteem } \\
\hline Time & $2.25(0.04)$ & $2.13(0.05)$ & 0.06 & 1,129 & 0.00 \\
\hline Group & & & 0.10 & 1,129 & 0.00 \\
\hline Time $x$ Group & & & 1.20 & 1,129 & 0.01 \\
\hline Treatment Group & $2.27(0.05)$ & $2.09(0.06)$ & & & \\
\hline Control Group & $2.24(0.06)$ & $2.16(0.07)$ & & & \\
\hline \multicolumn{6}{|l|}{ Empathy } \\
\hline Time & $1.68(0.02)$ & $1.67(0.02)$ & 0.04 & 1,129 & 0.00 \\
\hline Group & & & 3.33 & 1,129 & 0.03 \\
\hline Time $x$ Group & & & 0.13 & 1,129 & 0.00 \\
\hline Treatment Group & $1.72(0.03)$ & $1.70(0.03)$ & & & \\
\hline Control Group & $1.64(0.03)$ & $1.63(0.03)$ & & & \\
\hline \multicolumn{6}{|l|}{ Optimism } \\
\hline Time & $2.34(0.04)$ & $2.39(0.05)$ & 1.43 & 1,143 & 0.01 \\
\hline Group & & & 2.45 & 1,143 & 0.02 \\
\hline Time x Group & & & 0.47 & 1,143 & 0.00 \\
\hline Treatment Group & $2.29(0.06)$ & $2.31(0.06)$ & & & \\
\hline Control Group & $2.39(0.07)$ & $2.48(0.07)$ & & & \\
\hline \multicolumn{6}{|l|}{ Pessimism } \\
\hline Time & $1.10(0.05)$ & $1.10(0.06)$ & 0.01 & 1,142 & 0.00 \\
\hline Group & & & 1.63 & 1,142 & 0.01 \\
\hline Time x Group & & & 0.16 & 1,142 & 0.00 \\
\hline Treatment Group & $1.15(0.07)$ & $1.18(0.08)$ & & & \\
\hline Control Group & $1.04(0.09)$ & $1.02(0.09)$ & & & \\
\hline \multicolumn{6}{|l|}{ Compassion } \\
\hline Time & $3.38(0.05)$ & $3.61(0.05)$ & 3.47 & 1,139 & 0.02 \\
\hline Group & & & 0.61 & 1,139 & 0.00 \\
\hline Time x Group & & & 0.01 & 1,139 & 0.00 \\
\hline Treatment Group & $3.35(0.07)$ & $3.58(0.07)$ & & & \\
\hline Control Group & $3.41(0.08)$ & $3.65(0.08)$ & & & \\
\hline \multicolumn{6}{|l|}{ Social Competence } \\
\hline Time & $1.98(0.04)$ & $2.00(0.04)$ & 0.73 & 1,142 & 0.01 \\
\hline Group & & & 0.01 & 1,142 & 0.00 \\
\hline Time x Group & & & 0.00 & 1,142 & 0.00 \\
\hline Treatment Group & $1.98(0.05)$ & $2.00(0.05)$ & & & \\
\hline Control Group & $1.98(0.06)$ & $2.01(0.06)$ & & & \\
\hline
\end{tabular}




\section{An Experimental Trial of a Dog-Training Program in a Juvenile Detention Center TECHNICAL APPENDIX}

Table A1 reports the list of items used to create the various outcome scales. Each scale corresponds to psychosocial constructs specified as outputs or short-term outcomes of participation in the dog-training program during logic model development. Survey items were adapted from existing scales, pilot tested by residents not involved in the study, and amended based on the results of the pilot before the start of the trial. Items were averaged to create a scale score for each construct, with higher scores indicating greater levels of self-esteem, empathy, optimism, pessimism, compassion, and social competence.

\section{Table A1: Scales and Items}

\begin{tabular}{|l|}
\hline Self-Esteem scale adapted from Rosenberg (1965) \\
\hline Response set: Strongly Agree (3) to Strongly Disagree (0) \\
\hline Pre-test Cronbach's alpha 0.69; post-test 0.74 \\
\hline I am at least as good as other people (W) \\
\hline I have a number of good and useful skills (W) \\
\hline I am able to do things as well as most other people \\
\hline I feel I do not have much to be proud of* \\
\hline On the whole, I am the person I want to be (W) \\
\hline I wish I could have more respect for myself* \\
\hline I certainly feel useless at times* \\
\hline At times I think I am no good at all* \\
\hline \\
\hline Empathy scale adapted from Bryant (1982) \\
\hline Response set: Strongly Agree (3) to Strongly Disagree (0) \\
\hline Pre-test Cronbach's alpha 0.62; post-test 0.59 \\
\hline It makes me sad to see a lonely person who can't find anyone to play with (W) \\
\hline People who kiss and hug in public are silly* \\
\hline I find it silly to cry out of happiness (W)* \\
\hline I really like to watch people open presents, even when I don't get a present myself \\
\hline Seeing people cry makes me feel like crying (W) \\
\hline I get upset when I see people being hurt (W) \\
\hline Even when I don't know why someone is laughing, I laugh too \\
\hline It's hard for me to see why someone else gets upset* \\
\hline I get upset when I see an animal being hurt \\
\hline Some songs make me so sad I feel like crying \\
\hline Grown-ups cry even when they have nothing to be sad about (W)* \\
\hline It's silly to treat dogs and cats as though they have feelings like people* \\
\hline I get mad when I see someone pretending to need help all the time (W)* \\
\hline
\end{tabular}




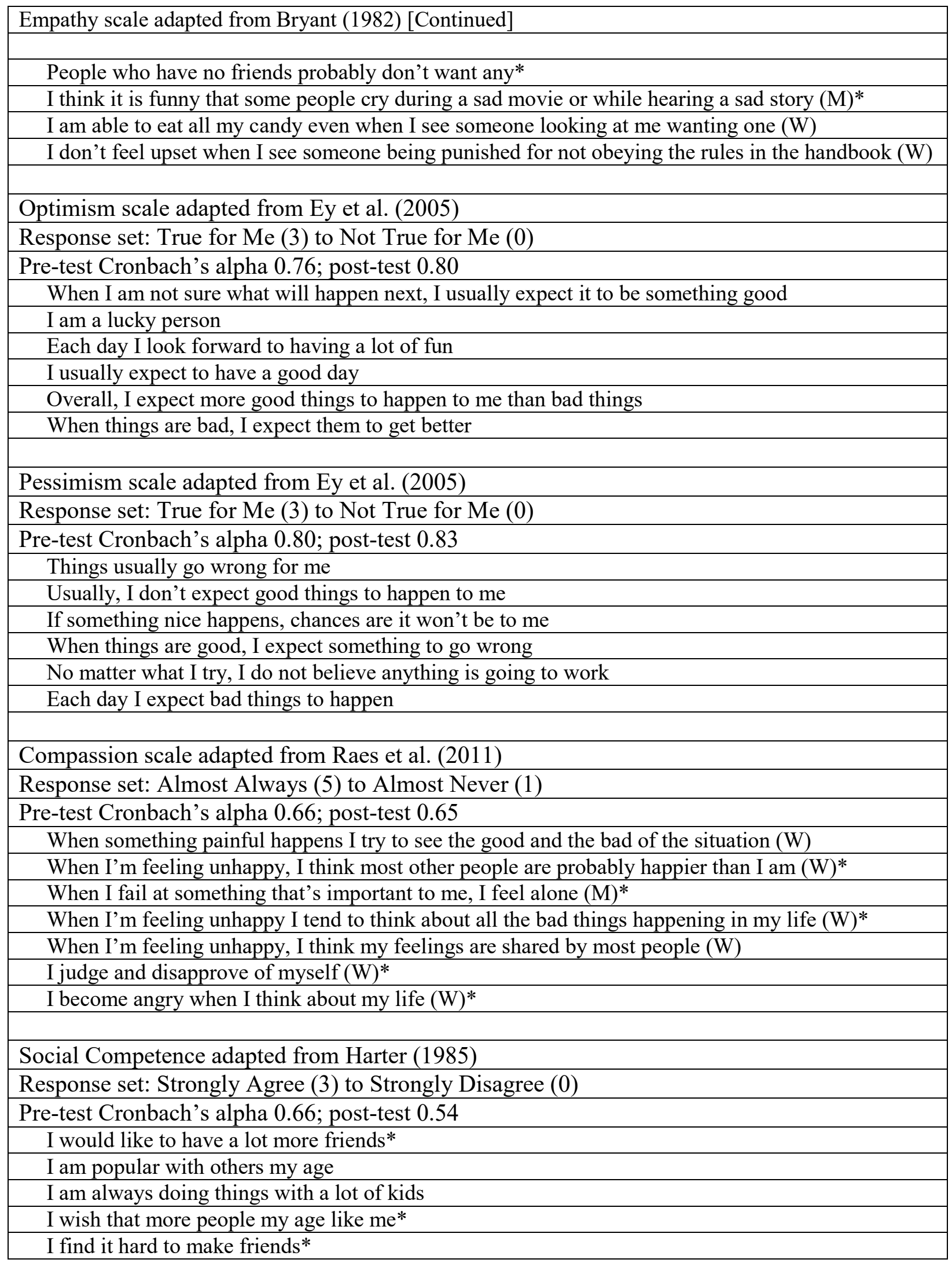

Key: *item reverse coded; (W) wording of existing scale item changed to suit participants 